\title{
Research on the Socialization Trend and Marketing Methods of Sports Dance
}

\author{
Yong $\mathrm{Xu}$ \\ Wuhan Business University \\ Wuhan, China 430050
}

\author{
Yazhen Li \\ Wuhan Sports University \\ Wuhan, China 430070
}

\author{
Jingwen Zhou \\ Wuhan College \\ Wuhan, China 430212
}

\begin{abstract}
With the rapid development of China's economy and the improvement of people's living standards, the fitness and entertainment industry has been widely loved as a third sunrise industry. The support of national policies has promoted the development of China's sports and fitness industry. This makes the socialization and industrialization of sports develop rapidly, which is the necessary way for the development of physical fitness in all countries of the world. This article will study the social trends and marketing methods of sports dance.
\end{abstract}

Keywords—sports dance; socialization trend; marketing method

\section{INTRODUCTION}

\section{A. Topic Background}

With the development of the economy and the continuous improvement of people's living standards, more people began to pay attention to leisure and entertainment life, paying more attention to physical health maintenance. As a widely accepted form of entertainment, sports dance is accelerating. Following music and sports dance, each stage of the human body has a rhythm, regular, stimulating action and creating different difficult dance movements and styling to form a segment of the finished dance. Although sports dance in China has just started, as a sport that combines fitness and entertainment, it will attract people to learn with its special charm, enriching people's spiritual life and promoting good health.

\section{B. Status}

In recent years, a large number of demands have led to the emergence of more and more sports dance training institutions. Many white-collar workers sit in the office during the day and face computer work. There is also less time for sports activities. This is why many members use their spare time to dance training activities after working hard during the day. With the rapid development of society, social activities have become the most basic activities of urban people. At the same time, sports activities have become a major part of urban life. Therefore, how to develop sports activities has become an important issue in urban construction, and sports dance training is also the base for urban dance. Therefore, the rise of sports dance training is an entertainment movement that appears to meet the needs of mass sports activities. Sports dance training institutions provide a venue for the spiritual life of the masses. Although sports dance training has become an important part of China's current mass entertainment and fitness with the continuous development of national fitness and mass fitness, the market scale has reached 100 billion. These training and education institutions are undoubtedly opened a wider space for the relatively weak mass entertainment art education in China. Nowadays, the international sports dance management training has stepped into the formal management and management road. However, China's dance training business has developed late, has a slow start, and is infrequent with international contacts, far behind the developed countries. Therefore, the most important thing for the current situation of sports dance in China is how to promote the development of sports dance, understand the development trend of sports dance and formulate relevant operational methods to become our topic.

\section{RESEARCH OBJECTS AND RESEARCH METHODS}

\section{A. Research Objects}

This paper aims to understand and analyze the current situation of sports dance, and through the communication and research of some dance training institutions, propose corresponding solutions and marketing methods.

\section{B. Research Methods}

1) Literature method: This article has consulted the relevant materials of sports dance according to the research content, most of which are from China Knowledge Network literature, Wuhan Sports Institute Library, etc., combined with "School Sports", "Sports Training", "Club Management" and other courses in universities to understand the origin and development process and current situation of sports dance, and analyze it.

2) Access survey method: After a preliminary understanding of the origin and development of sports dance, 
study dance training institutions, analyze the problems of dance training and the dance development.

\section{SPORTS DANCE SOCIALIZATION TREND}

\section{A. The Meaning of Socialization of Sports Dance}

The music, art, sports and entertainment and many other factors of sports dance are more entertaining, with strong technical and artistic characteristics. It is a kind of performance dance, and the dance is also called contemporary international standard dance. Since the launch of the national fitness campaign, more and more people are interested in sports dance, and even some ordinary colleges have added sports dance courses. Through the practice of sports dance, physical coordination and physical quality have been greatly improved.

The development of Chinese sports dance and social change are also inseparable. Because sports dance can promote communication and cultivate physical and mental health, creativity, and special functions that reflect the value of life, sports dance is loved by the people with its rich connotation, extensive social interaction and rich and colorful charm. The socialization of sports dance is to exercise together in a certain social environment under certain social management conditions, and participate in sports dance as a lifelong physical exercise habit. The socialization of sports dance is the intrinsic essence of sports culture and the inevitable result of development.

\section{B. The Necessity of Socialization of Sports Dance}

At present, the rapid development of the social economy, the rising material living standards and the corresponding accelerated pace of life, in a fast-paced life, people began to feel certain work pressure, people began to pay attention to their own health. Sports dance not only enables people to achieve the original goal of physical fitness, but also enriches people's spiritual life and exercise. Sports dance can strengthen the body; sports dance pays more attention to dance music and spiritual comfort. In addition, sports dance can make new friends and improve interpersonal skills.

\section{The Social Value of Sports Dance}

1) The value of physical fitness: Exercisers can not only exercise better when they participate in sports dance, but also have obvious effects on physical strength. However, in this respect, some scholars believe that the leisure and fitness of sports dance is not a formal sport. However, some foreign scholars have carried out research on sports dance to improve human physiology. Studies have shown that sports dance has obvious effects on improving blood pressure, heart rate, or urine protein, so it has a certain fitness value. People are free to choose the rhythm of sports dance, so sports dance is more suitable for people of different ages. Exercisers often participate in physical exercise, you can find some diseases, chronic diseases or knee injuries, etc. and have improved those, and even exercise prescription "dancing" listed, therefore, sports dance, rehabilitation function. At the same time, people often participate in sports dance, which has a great effect on the shaping of the body and is conducive to the development of coordination and control of the body.

2) Good human kinematics value: Kinematics is a sports science. Relatively good systemic and theoretical, it will better guide sports practice and achieve the goal of scientific exercise. Sports dance forms a distinctive, special and unique style while maintaining the standard of human movement. It enriches the connotation and content of sports dance and increases people's love for sports dance. It is a unique and effective way to maintain body shape and exercise health.

3) Social communication value: Regular exercisers participate in sports dance movements, and when sports establish correct values, they must know the true meaning of social interaction. Sports dance is a two-person sport that has a wealth of experience in music, sports, convenience and communication between participants. Through the sports dance exchanges with our partners, we can learn about different humanities and social customs. Such as tango, it is a good reflection of the social communication function of sports dance.

4) Certain aesthetic value: Sports dance is very artistic and sporty, and it is an aesthetic movement. By practicing sports dance, people can be more slender, more harmonious, more graceful, more energetic and energetic. This allows people to pursue a noble state of mind and satisfy the satisfaction of their own desires, as well as influence the aesthetic concept that influences dance. In addition, sports dance has a high appreciation value. The position of the dancer's body changing, along with the music, forms a dynamic, elegant and colorful dynamic picture. At the same time, let people enjoy their beautiful gestures, movements, skirts and sweet music in emotional adjustment, selfappreciation and aesthetic enjoyment.

\section{Development Trend of Sports Dance}

Sports dance is also known as international standard dance. It originated in the United Kingdom, and Europe and the United States are also the social dance countries of the contemporary international popular sports. It combines music, skills, physical health and performance into a whole. The cultural and entertainment connotation and the characteristics of sports competitions are the establishment of a friendship between people and the cultivation of sentiment. It is a good way of physical exercise. In the 1980s, the American Brigham Young University Dance Troupe came to China to perform sports dances. The Chinese people were initially aware of this kind of sports dance from the British origin that was extended by social dance. In the following days, sports dance won people's love with his novel dance mode and unique dance movements. In 1999, it was officially included in the competition, which further promoted the development of sports dance.

Today, the rapid development of Chinese sports dance has made China more and more important in the world sports dance platform. However, there are some problems in sports dance in China. For example, the level is relatively low and the 
development of different regions is uneven. Southern cities such as Shenzhen and Guangzhou have become the leading regions for Chinese sports dance. Chinese sports and dance athletes are also affected by various factors. Sometimes, although they can train and advance in a short period of time, they still have some distance in terms of physical fitness compared with athletes in high-level countries in the world. In sports dance teaching, the uneven technical level of dance coaches makes the development of Chinese sports dance more uneven.

1) Competitive trend: With the development of sports dance, more and more children began to learn sports dance. China's sports dance has developed more rapidly in recent years. As sports dance becomes more and more professional, more and more people are engaged in professional sports dance athletes or related professions. China adheres to the introduction of ideas and teaching methods of sports dance in develops advanced national. Through continuous learning, digestion and absorption, it improves the level of competition and plays an important role in the Chinese sports dance toward the world. Our sports dance competitions are approved by the authoritative organization of international sports dance. China's sports dance is constantly updated, injecting vitality and vitality, and at the same time endowing the competition between modern and natural. The competition in the international sports dance stage cannot be underestimated.

2) Entertainment trends: The improvement of living standards has made people pay more attention to their entertainment life. The popularity of square dance and social dance laid the foundation for the spread of sports dance. Sports dance itself has a strong entertainment and performance, which brings people a wonderful visual feast and promotes more people to learn sports dance. Most people do not pursue sports and sports competitions. They only want to keep fit, cultivate their sentiments, and expand their social reach. Enrich people's spiritual life and increase leisure activities in their spare time.

\section{MARKeTING Methods OF SPORTS DANCE}

\section{A. Improving the Public's Understanding of Sports Dance}

At the current level of social sports development, relevant departments of the society should raise their awareness of sports dance and understand the development trend of sports dance. Because sports dance is very entertaining, sports dance competitions are often reported by TV broadcast media; some magazines or websites will broadcast sports dance competitions; the socialization of sports dance development requires improving people's understanding of sports dance, strengthening publicity to further promote the development of sports dance.

\section{B. Sports Dance Toward School}

Increasing the sports dance course in school physical education is of great significance to students. Cultivating talent is the most basic function of school physical fitness and entertainment, and for lifelong sports, sports dance can meet the diversified development of demand. Sports dance into the school is conducive to improving the level of sports and dance in the country. It can also enhance students' physical fitness and enrich students' spare time, which plays an important role in the future development of sports dance. In addition, sports dance is an unrestricted factor, such as age, gender, or physical condition, reflecting its unique advantages, each person can combine their own characteristics to exercise. Sports dance can not only choose the music rhythm and frequency of movement, but also the date to finally achieve the purpose of fitness. Students of sports dance, as a lifelong exerciser. They often participate in sports dance sports, not only can exercise, enrich their after-school life, but also improve their social communication skills and further promote their individualized development.

\section{Reforming the Organization Form of Sports Dance}

The reform of sports dance should pay more attention to self-development education according to the change of time, and it needs to evolve into a form of learning-type sports dance, which is conducive to the development and progress of sports dance. The organization form of modern sports dance is divided into two categories: one is school education, and the purpose is to improve the professional skills of dance balance. Most of the students will play games regularly. This type of person is a sports dance professional athlete. The second category is a sports dance training club for the purpose of making profits. There are more group clubs that expand the range of friends and trainees to strengthen their physical fitness and increase their entertainment life. In addition, young people are concentrated in colleges and universities to improve the competitive skills of sports dance in China in the form of appropriate amateur training activities.

\section{Cultivating High-quality Social Sports Dance Instructors}

High-quality social sports dance instructors play a vital role in promoting sports dance. It affects students' perceptions of sports dance and basic sports dance. All colleges and universities in China should fully develop and improve the content of international sports dance as a teaching material for teacher training, giving priority to the development of teaching teachers. While accelerating the development of the number of social sports dance teachers, we must also improve their quality. High-quality sports dance coaches should have a high moral and ethical quality, a knowledgeable knowledge, a strong body and sufficient energy, and a wealth of business skills. In this way, the sports and dance social instructors can take the lead in the development of sports dance, promote the development of sports dance, and the progress of society.

\section{COUNTERMEASURES FOR THE DEVELOPMENT OF SOCIAL SPORTS DANCE TRAINING INSTITUTIONS}

\section{A. Improving the Status of Teachers}

A good teacher is the key to physical dance teaching. Only excellent teachers can lead students to conduct regular and effective sports dance training, and can teach students to teach students to do things for others. It is a comprehensive development of students. However, at present, the quality of 
teachers in many dance training institutions is low. There is no standard for recruiting teachers. Many teachers who are not professional sports dances have begun to engage in sports dance teaching. Therefore, we are now very urgent to improve the status of teachers in sports dance. China's two major sports dance associations, sports associations and dance associations will conduct formal sports dance teacher training and assessment every year. As a sports dance teacher, continuous learning and progress is our responsibility and obligation, and they invite famous sports and dance professional players to teach sports dance professional skills every year, so it is very important to study every year. At present, most of the dance training institutions have been gold, silver and bronze medals for teaching routines, so it is more necessary for sports dance coaches to continue their training and progress with the times.

Sports dance coaches also need constant learning and progress, instead of just teaching some past things and eating old. Teachers also need to use the holiday to get out and do sports and dance exchanges and learning. They should think about and study the dance styles of other sports dance instructors, the division and understanding of music, and take the essence and get rid of its dross and apply to themselves in the dance teaching, go to the competition and watch the game, and learn what you need from your opponent.

\section{B. Management and Teaching Develop Simultaneously}

For sports dance training institutions, the important thing to run a dance club is the technical level, knowledge reserve and quality of dance teaching. But the most important thing for the operation of the club is a good leader. A club only has excellent leader with strong business ability can lead the whole club forward and play a decisive role in the development of the whole club. He decides the operation status of the whole club.

But now many managers do not have more professional knowledge management skills, managers need to focus on learning management knowledge, enhance their personal charisma, and promote staff unity. This is something that every manager needs to strengthen. For a relatively large dance club, the unity and quality of the people becomes a crucial matter. You need to go to the field to experience, and you can only present your own opinions after you have experienced it yourself, instead of doing some surface work, such as lectures.

\section{The Government Promotes the Construction of Relevant Laws and Regulations}

The government intervened to manage learning clubs and set relevant standards. Individual schools can only enroll students if they meet the relevant standards. Communicate education and integration for dance training institutions that do not meet non-compliance standards. For those dance clubs that do not meet the standards and are of poor quality, they are ordered to suspend business. Organize various sports dance competitions and enhance the understanding of sports dance through competitions. Teacher training is often held to continuously improve the technical level of teachers. Establish a good feedback reporting channel.

\section{Increasing Competition and Performance Opportunities}

Dance associations and sports associations focus on smallscale competitions that are not based on profit. Before the game, we need to pay attention to communication with the organizers, do a good job of propaganda, attract more teachers to lead students to the competition, and set up corresponding bonuses. To do some public welfare performances, you can not only exercise the performance of students, but also increase the visibility of sports and dance institutions.

\section{E. Increasing Publicity and Changing Imbalance}

The different attitudes of sports dances in different regions have led to regional imbalances. Therefore, areas with relatively weak development of sports dances need to increase publicity and promote the development of local sports dance. Different courses for different students, teaching students in accordance with their aptitude. Beginner, intermediate, high class and art class, have different learning intensity and learning content and courses are diversified.

\section{CONCLUSION}

As a kind of mass exercise, sports dance can not only achieve the purpose of fitness, but also strengthen emotional communication. After the combination of sports dance and music melody, it has a higher appearance and more obvious artistry, giving more beauty. Sports dance as a kind of leisure sports, project communication is very extensive and fast. Sports dance originated from the court social dance, and later popularized. In modern times, it is developing in two aspects, one is competitive and the other is entertainment and fitness. In the days to come, in the days of national fitness development, sports dance will become a kind of fitness development, more social and popular.

\section{REFERENCES}

[1] Wei Xiaoyun, Zhang Wei, Yang Wenlong. Development and Ways of Socialization of Sports Dance[J]. Journal of Hengshui University, 2007(3): 124-126.

[2] Si Liyan, Wang Ruifang. The Path of Socialization of Sports Dance[J]. Journal of Suzhou University, 2013, 28(9): 90-91

[3] Yu Lu. Research on Marketing Strategy of Business Sports Dance Club [D]. Wuhan Institute of Physical Education, 2010.

[4] Li Xuefei. On Marketing Mix in Sports Market[J]. Zhejiang Sports Science, 2001, 23(5): 34-36.

[5] Huang Qing. The status quo and thinking of industrial marketing of domestic dance sports events [D]. Wuhan Institute of Physical Education, 2009. 